\title{
Forgeability of AZ Series Magnesium Alloy produced by Twin Roll Casting
}

\author{
Nao Ozawa ${ }^{1}$, Shinichi Nishida ${ }^{1}$, Toshio Haga ${ }^{2}$, Junshi Ichikawa ${ }^{1}$, Yuta Kashitani ${ }^{1}$, \\ Ryosuke Okushima $^{1}$, Yujiro Nitta ${ }^{1}$, Atsuhiro Aoki ${ }^{1}$, Yuto Takigawa ${ }^{1}$, Hayato Aso ${ }^{1}$, \\ Hideto Harada ${ }^{1}$, Akihiro Watanabe ${ }^{1}$
}

${ }^{1}$ Department of Mechanical Science and Technology, Gunma University, Japan

${ }^{2}$ Osaka Institute of Technology, Japan

\begin{abstract}
Plastic forming of magnesium alloy is hardly reported because of its low forgeability. The productions of magnesium alloy are mainly produced by casting. Typical wrought magnesium alloy is AZ31. Magnesiumaluminum alloy indicates maximum elongation when the composition includes 3\% aluminum. When the magnesium alloy includes over 3\% aluminum, its elongation slightly decreases. Therefore, AZ31 that include 3\% aluminum and $1 \%$ zinc is generally used for plastic forming. The more increasing aluminum composition, the larger $0.2 \%$ proof stress becomes. However its forgeability is decreasing because of precipitation of $\beta$ phase such as Mg17Al12. It is supposed that the $\beta$ phase is refined by rapid cooling casting process such as twin roll casting. In this paper, the magnesium alloy thick sheet of AZ91, AZ121 and AZ131 for hot forging, that include 9\%, $12 \%$ and $13 \%$ aluminum composition respectively, was produced by twin roll strip casting process. And the forgeability of high aluminum containing magnesium alloy was investigated by die forging. As a result, it was possible to forge their magnesium alloys.
\end{abstract}

Keywords-Magnesium alloy AZ91 AZ121 AZ131, Hot forging, Twin roll strip casting, Forgeability

\section{INTRODUCTION}

Magnesium alloy is getting the attention because it is the lightest weight structural material. Forgings has some properties such as the high toughness and the high productivity. However, the forgings of magnesium alloy is hardly reported [1]-[5]. The elongation at room temperature of magnesium is smaller than that of aluminum or steel because magnesium has hexagonal close-packed structure which slip plane is almost limited to basal plane. The production of magnesium alloy is generally by casting. Therefore the demand of wrought magnesium alloy is little. The examples of wrought magnesium alloy are AZ31, AZ61 and AZ80. Magnesium-aluminum alloy indicates maximum elongation when the composition includes 3\% aluminum.
When the magnesium alloy includes over 3\% aluminum, its elongation slightly decreases. Therefore, AZ31 that include $3 \%$ aluminum and $1 \%$ zinc is generally used for plastic forming. The more increasing aluminum composition, the larger $0.2 \%$ proof stress becomes. However its forgeability is decreasing because of precipitation of $\beta$ phase such as Mg17Al12. It is supposed that the $\beta$ phase is refined by rapid cooling casting process such as twin roll casting. In this paper, the magnesium alloy thick sheet of AZ91, AZ121 and AZ131 for hot forging, that include 9\%, 12\% and 13\% aluminum composition respectively, was produced by different diameter twin roll strip casting process. And the forgeability of high aluminum containing magnesium alloy was investigated by die forging.

\section{TWIN ROLL STRIP CASTING}

Fig.1 shows the photograph of different diagram twin roll strip caster. Three kind of magnesium alloy, AZ91 (Mg9Al-1Zn), AZ121 (Mg-12Al-1Zn) and AZ131 (Mg-13Al$1 \mathrm{Zn}$ ), were casted by this experimental device. The target thickness of cast strip is over $14.5 \mathrm{~mm}$. Both roll materials are copper. Upper roll diagram is $300 \mathrm{~mm}$. Lower roll diagram is $1000 \mathrm{~mm}$. Both roll width is 100 $\mathrm{mm}$. Upper roll solidification length is $100 \mathrm{~mm}$. Lower roll solidification is $350 \mathrm{~mm}$. Roll speed is $2 \mathrm{~m} / \mathrm{min}$. Fig. 2 and Fig. 3 show the AZ131 cast strip. The length of cast strip was over $1 \mathrm{~m}$. And the thickness was over $20 \mathrm{~mm}$. It was possible to cast the other magnesium alloy strips.

\section{FORGING EXPERIMENTAL CONDITIONS}

Fig.4 shows the servo press machine (SDE1522, AMADA MACHINE TOOLS CO.,LTD.) for hot forging. The maximum pressure loading of this machine is 1500 $\mathrm{kN}$. Stroke length is $225 \mathrm{~mm}$. Generally, in hot forging, the blank forging material is forged soon after taking from heating furnace. In this study, hot forging was operated with the heating die by inserted the cartridge heater to control the forging temperature. Fig.5 shows the photograph of forging die. Heating temperature was 
$350^{\circ} \mathrm{C}$. The die temperature was controlled by PID control and coolant water. The forging blank was kept to be $350^{\circ} \mathrm{C}$ before forging in the heating die.

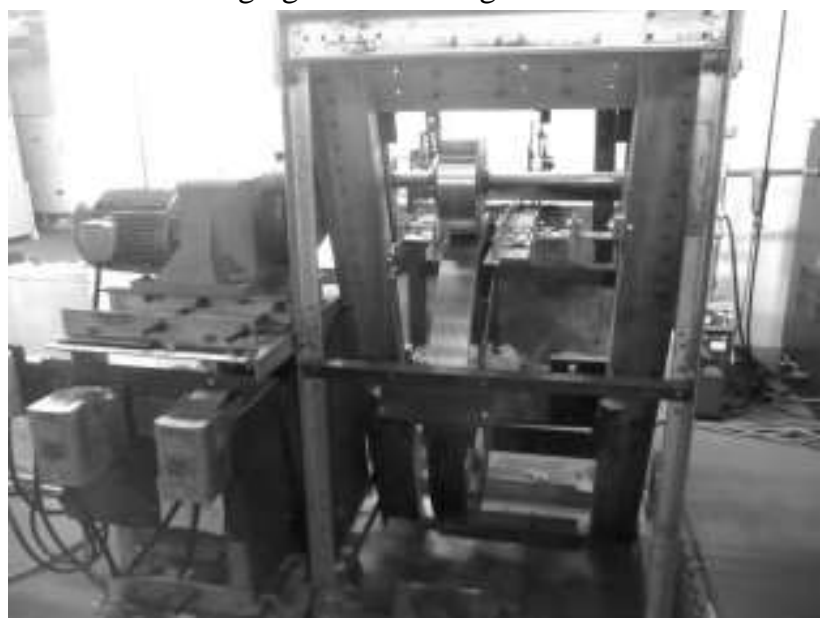

Fig.1: Photograph of different diagram twin roll strip caster

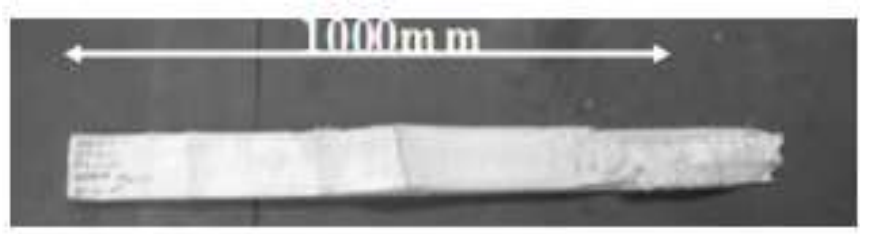

Fig.2: AZ131 magnesium alloy strip produced by twin roll caster

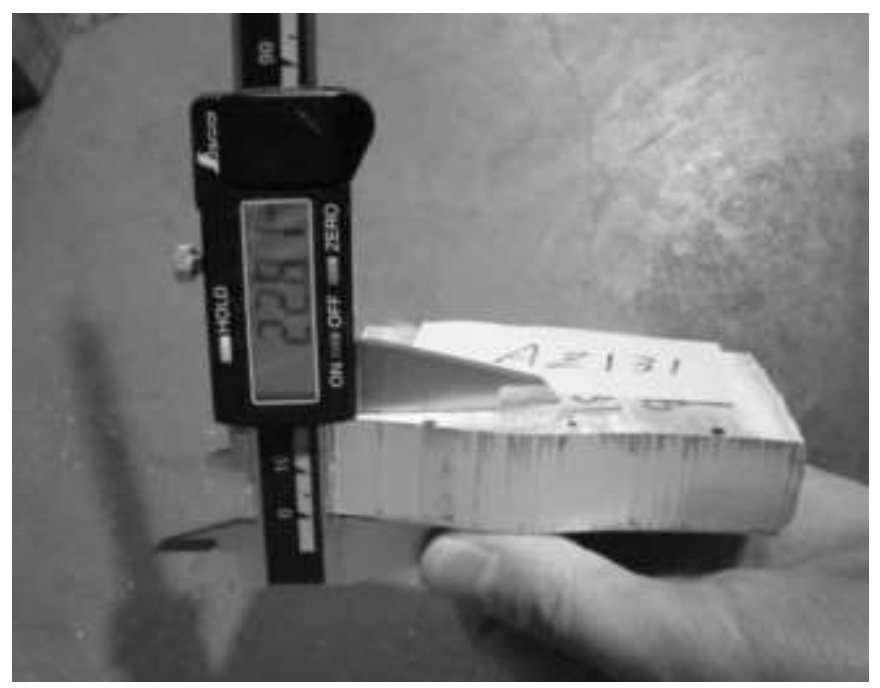

Fig.3: Cross section of roll casted AZ131 strip

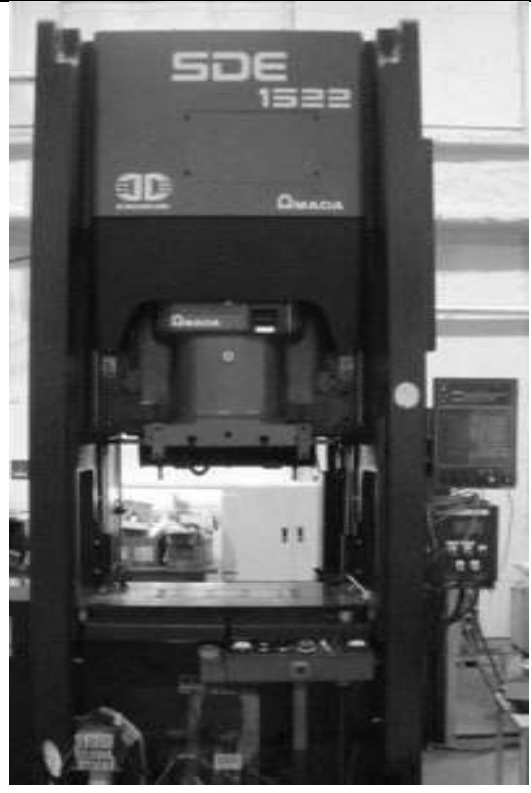

Fig.4: Servo press machine (SDE1522, AMADA MACHINE TOOLS CO.,LTD.)

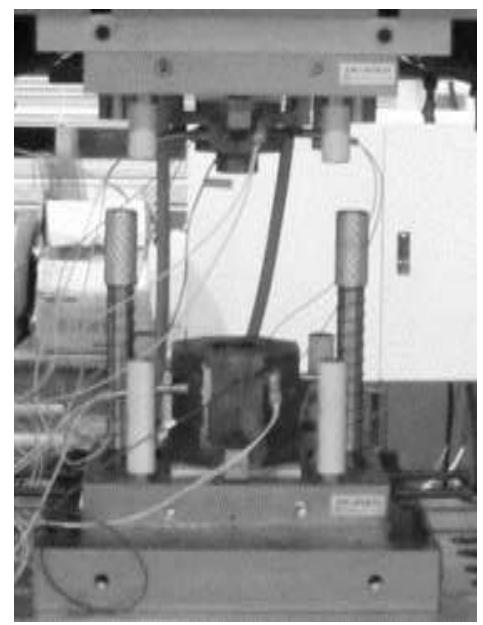

Fig.5: Forging die

The forging blank was cut by wire electrical discharge machine. Outer diameter of blank is $50 \mathrm{~mm}$. The thickness was $14.5 \mathrm{~mm}$. The strip was cutting by a lathe to make the blank with the thickness $14.5 \mathrm{~mm}$ from 20 $\mathrm{mm}$. Fig. 6 shows the design of forging die. This die shape was the simulated scroll for the car air conditioner compressor. The maximum scroll wall thickness was 5 $\mathrm{mm}$, and the minimum wall thickness was $2 \mathrm{~mm}$. The wall thickness was slightly changed from center to outer. The designed value of wall height was $25 \mathrm{~mm}$.

Table 1 shows the experimental conditions. Press length was $9.5 \mathrm{~mm}$. Forging temperature was $350{ }^{\circ} \mathrm{C}$. Forging was operated after measuring temperature of die. Forging motion was selected as constant speed motion. Punch speed was $10 \mathrm{~mm} / \mathrm{sec}$. Lubricant was used. The lubricant was applied to forging blank by brush before setting into the die. Keeping time in the die was $2 \mathrm{~min}$. The 
temperature of forging blank was same to the temperature of heating die.

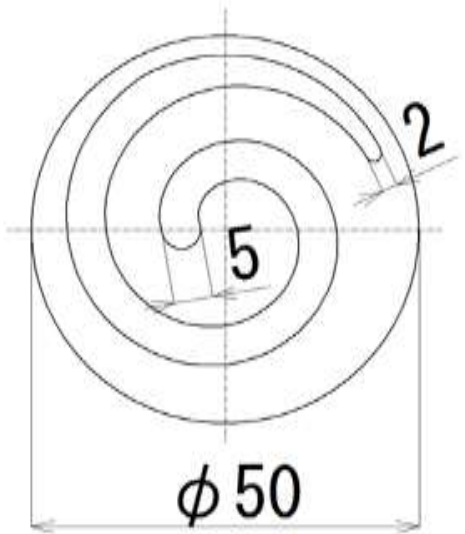

Fig.6: Design of simulated scroll (wall height $25 \mathrm{~mm}$ )

Table.1: Experimental Conditions

\begin{tabular}{|c|c|c|c|}
\hline Test No. & 1 & 2 & 3 \\
\hline Material & AZ91 & AZ121 & AZ131 \\
\hline Size $/ \mathrm{mm}$ & \multicolumn{3}{|c|}{$\square 50 \times \mathrm{t} 14.5$} \\
\hline Extrusion length $/ \mathrm{mm}$ & \multicolumn{3}{|c|}{9.5} \\
\hline Die height position $/ \mathrm{mm}$ & \multicolumn{2}{|c|}{430} \\
\hline Temperature $/{ }^{\circ} \mathrm{C}$ & \multicolumn{2}{|c|}{350} \\
\hline Motion & \multicolumn{2}{|c|}{ Constant speed motion } \\
\hline Velocity $/ \mathrm{mm} \cdot \mathrm{s}^{-1}$ & \multicolumn{2}{|c}{10} \\
\hline
\end{tabular}

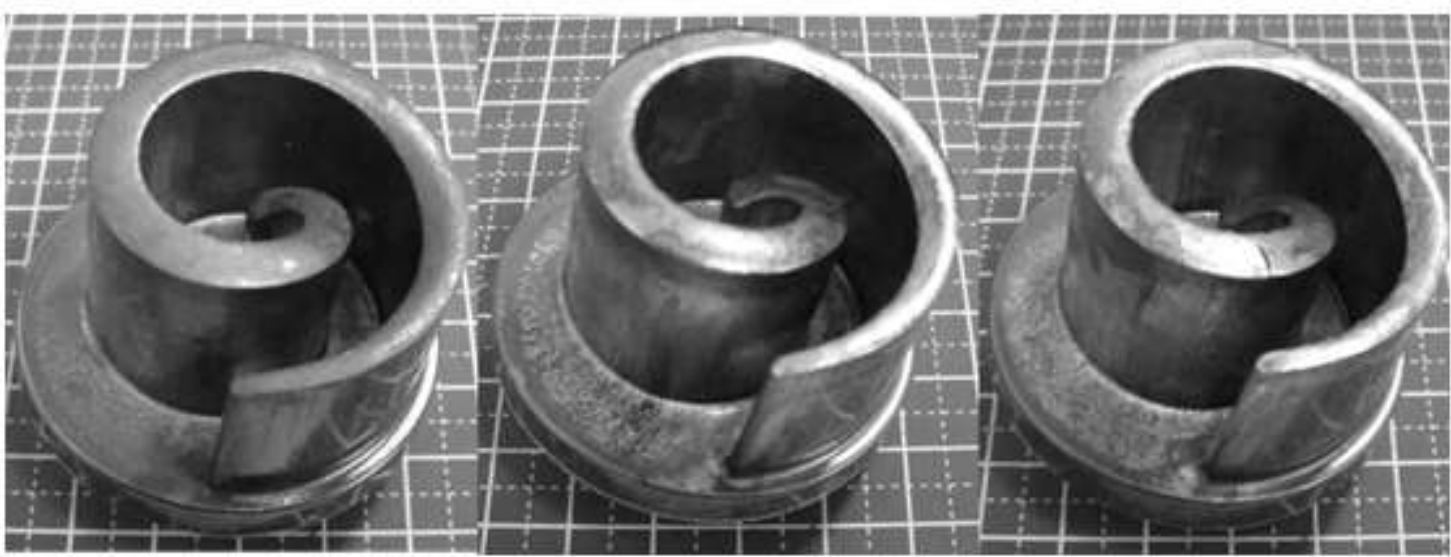

Fig.7: Forged parts (Left: AZ91, Center: AZ121, Right: AZ131)

Fig.8 shows the relationship between the forging force, punch position and time of AZ91. Forging started at the punch position $9.5 \mathrm{~mm}$. The maximum load $469 \mathrm{kN}$ was observed at press length $2.1 \mathrm{~mm}$ (punch position $7.4 \mathrm{~mm}$ ). After peak load, the forging load was downed to finish forging. Forging force was almost constant after press length $5.2 \mathrm{~mm}$ (punch position $4.3 \mathrm{~mm}$ ). Forging load might be rapidly increased after completely filling in the die. This forging was not filled completely, thus the forging load was not increased after press length $2.1 \mathrm{~mm}$. Fig.9 shows the relationship between the relationship between the forging force, punch position and time of AZ121. Fig.10 shows the relationship between the

\section{RESULTS AND DISCUSSIONS}

Fig.7 shows the photographs of forged magnesium alloy. The notable difference for the forged shape was not observed. In addition, forged scroll height had not difference. However, the cracks was observed on the surface of forged AZ131, white circle shown in Fig.7. Tensile stress was occurred to the direction of radial and circumferential on the surface of top of scroll wall, so that the stress was biaxial tensile stress. It was supposed that the crack was caused by biaxial tensile stress because of the poor formability of magnesium alloy. And it was supposed that the crack was caused not only at final stage of forming but also at the stage of forming the scroll wall. The crack was might cause at the maximum forging load (press length $1.7 \mathrm{~mm}$ ). Because the surface enlargement of the scroll tips was not changed during forging, thus the tensile stress on the surface of tip was not increase rapidly. It was possible to forge the thick strip of AZ91, AZ121 and AZ131 magnesium alloy produce by the different diagram twin roll caster. It is needed to research the forging condition to prevent the crack. relationship between the forging force, punch position and time of AZ131. The maximum forging load of AZ121 was $431 \mathrm{kN}$, and the that one of AZ131 was $448 \mathrm{kN}$. The notable difference of maximum forging load was not observed about each amount of aluminum content. It was supposed that the variation of forging load was caused by coating technique of the lubricant. 


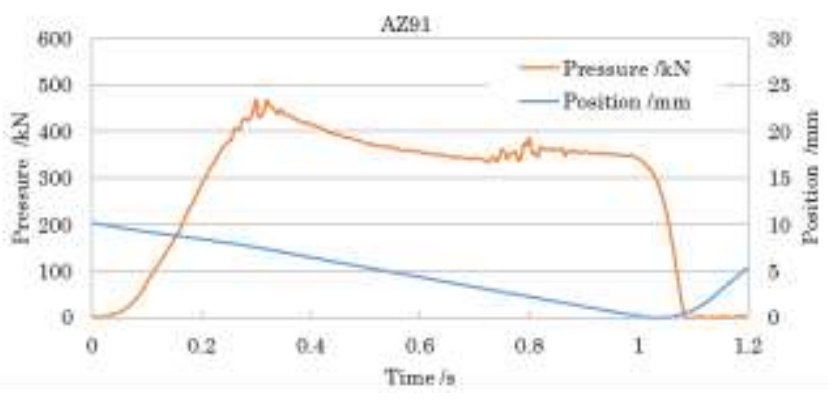

Fig.8: Pressure-Time and Slide position-Time diagram (AZ91)

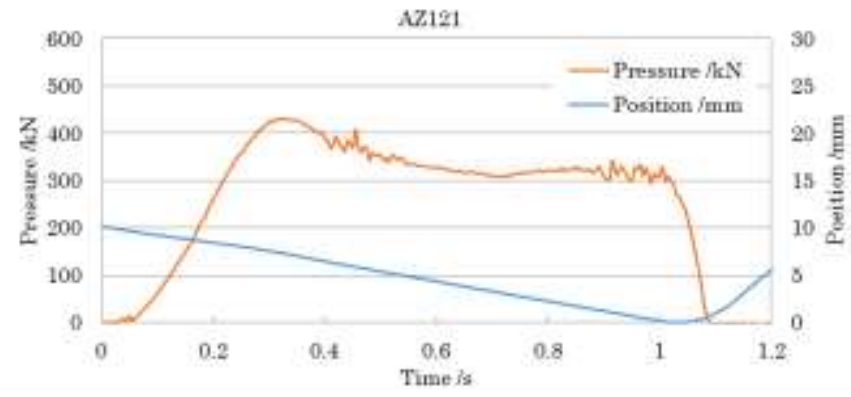

Fig.9: Pressure-Time and Slide position-Time diagram

(AZ121)

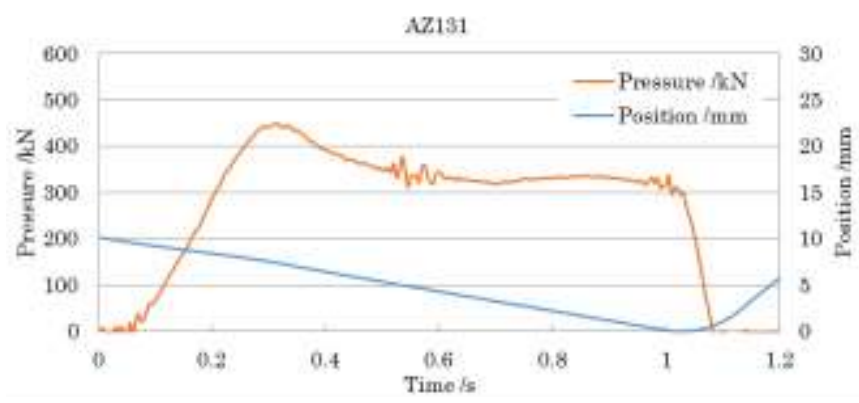

Fig.10: Pressure-Time and Slide position-Time diagram (AZ131)

\section{CONCLUSION}

The magnesium alloy thick sheet of AZ91, AZ121 and AZ131 for hot forging, that include 9\%, 12\% and 13\% aluminum composition respectively, was produced by different diameter twin roll strip casting process. And the forgeability of high aluminum containing magnesium alloy was investigated by die forging. It was possible to produce the magnesium alloy strip with over $20 \mathrm{~mm}$ thickness by different diagram twin roll strip caster. It was possible to forge the thick strip of AZ91, AZ121 and AZ131 magnesium alloy produce by the different diagram twin roll caster. The notable difference for the forged shape was not observed. The cracks was only observed on the surface of forged AZ131. The notable difference of maximum forging load was not observed about each amount of aluminum content.

\section{REFERENCES}

[1] Jing Zhang, Hao Huang and ChengBo Yang, Effects of hot ring forging on microstructure, texture and mechanical properties of AZ31 magnesium alloy, Materials Science and Engineering: A, 679(2), 2017, 20-27.

[2] Juqiang Li, Juan Liu and Zhenshan Cui, Microstructures and mechanical properties of AZ61 magnesium alloy after isothermal multidirectional forging with increasing strain rate, Materials Science and Engineering: A, 643(3), 2015, 32-36.

[3] A. Salandari-Rabori, A. Zarei-Hanzaki, S.M. Fatemi, M. Ghambari and M. Moghaddam, Microstructure and superior mechanical properties of a multi-axially forged WE magnesium alloy, Journal of Alloys and Compounds, 695(5), 2017, 406-413.

[4] Anna Dziubińska, Andrzej Gontarz, Karina Horzelska and Paweł Pieśko, The Microstructure and Mechanical Properties of AZ31 Magnesium Alloy Aircraft Brackets Produced by a New Forging Technology, Procedia Manufacturing, 2, 2015, 337341.

[5] K.B. Nie, K.K. Deng, X.J. Wang, F.J. Xu, K. Wu and M.Y. Zheng, Multidirectional forging of AZ91 magnesium alloy and its effects on microstructures and mechanical properties, Materials Science and Engineering: A, 624(29), 2015, 157-168. 